\section{Statistics in the era of COVID-19}

Measuring lockdowns with doubling time

\begin{tabular}{|c|c|c|}
\hline $\begin{array}{l}\text { The key to understanding } \\
\text { SARS-CoV-2 (COVID-19) } \\
\text { transmission is understanding } \\
\text { the exponential growth of viral } \\
\text { transmissions. The problem is } \\
\text { that the concept of exponential } \\
\text { growth is challenging for many } \\
\text { to understand and interpret, } \\
\text { including policymakers who } \\
\text { need to make quick and } \\
\text { informed decisions. Dr Biljana } \\
\text { Stangeland, Executive Director/ } \\
\text { Chief Scientific Officer at Alv } \\
\text { B, Norway, has been using } \\
\text { doubling time - the amount of } \\
\text { time COVID-19 cases takes to } \\
\text { double - to provide statistics } \\
\text { that are easier to interpret. By } \\
\text { investigating the doubling time } \\
\text { in Norway and Europe during } \\
\text { the first COVIID-19 wave, Dr } \\
\text { Stangeland aims to help better } \\
\text { understand the effectiveness of } \\
\text { lockdown in reducing SARS- } \\
\text { CoV-2 transmission. }\end{array}$ & $\begin{array}{l}\text { tatistics are drivers of decisions } \\
\text { in businesses, governments, and } \\
\text { manstitutions other modernised societal } \\
\text { hire entire departmerts clubs that of statistical } \\
\text { analysts, and their adoring fans who use } \\
\text { them as the basis of their arguments, } \\
\text { to film studios that employ executives } \\
\text { to commission new movies based on } \\
\text { statistics, with their target customers } \\
\text { who now obsess over film review scores } \\
\text { on websites like Rotten Tomatoes, there } \\
\text { is a collective statistical saturation in all } \\
\text { corners of our society. } \\
\text { No situation has made the tangible } \\
\text { importance and pervasiveness of statistics } \\
\text { more apparent than COVID-19. Every } \\
\text { news channel was suddenly tasked with } \\
\text { explaining epidemiological data. Every } \\
\text { government announcement could now } \\
\text { involve science advisors presenting } \\
\text { graphs on the number of COVID-19 } \\
\text { cases. Governments themselves were } \\
\text { in the unprecedented situation of a } \\
\text { pandemic, one which required quick } \\
\text { public health decisions based on } \\
\text { epidemiological data. }\end{array}$ & $\begin{array}{l}\text { A potent combination of the exponential } \\
\text { growth that viruses undergo as they } \\
\text { infect any given population and the } \\
\text { length of time it would take for people } \\
\text { to develop symptoms, exacerbated the } \\
\text { potential damage that the SARS-CoV-2 } \\
\text { (COVID-19) could cause. Throughout } \\
\text { the pandemic, governments have had } \\
\text { to understand these facts and statistical } \\
\text { projections in their countries, to enact } \\
\text { effective public health policy. Knowing } \\
\text { the perfect time to enact lockdowns, } \\
\text { shut schools and services, and ensure } \\
\text { people work at home, has been key to } \\
\text { saving lives. Practically speaking, this } \\
\text { has required policymakers to look at the } \\
\text { latest epidemiological data, including } \\
\text { the mortality rate and the number of } \\
\text { COVID-19 cases. That means numbers, } \\
\text { statistics, and graphs. And these graphs } \\
\text { are incredibly difficult to understand. } \\
\text { EXPONENTIAL GROWTH } \\
\text { Being able to understand the number } \\
\text { of cases as well as predict the future } \\
\text { number of cases and deaths requires } \\
\text { an understanding of exponential } \\
\text { growth. Exponential growth refers to } \\
\text { situations where an increasing quantity of } \\
\text { something also increases its growth rate. } \\
\text { The number of cases of a disease such as } \\
\text { COVID-19 will grow exponentially, if left } \\
\text { unrestrained, as more carriers of SARS- } \\
\text { CoV-2 virus will infect more people, all } \\
\text { of whom will go on to infect even more } \\
\text { people. As scientists, journalists and other } \\
\text { officials save noted, not understanding } \\
\text { exponential growth can be a key factor in } \\
\text { the complacency of individuals ignoring } \\
\text { public health measures. } \\
\text { But it wouldn't be fair to blame the } \\
\text { general public for being too ignorant } \\
\text { to understand the measures, or too } \\
\text { inconsiderate to practice such measures. }\end{array}$ \\
\hline
\end{tabular}

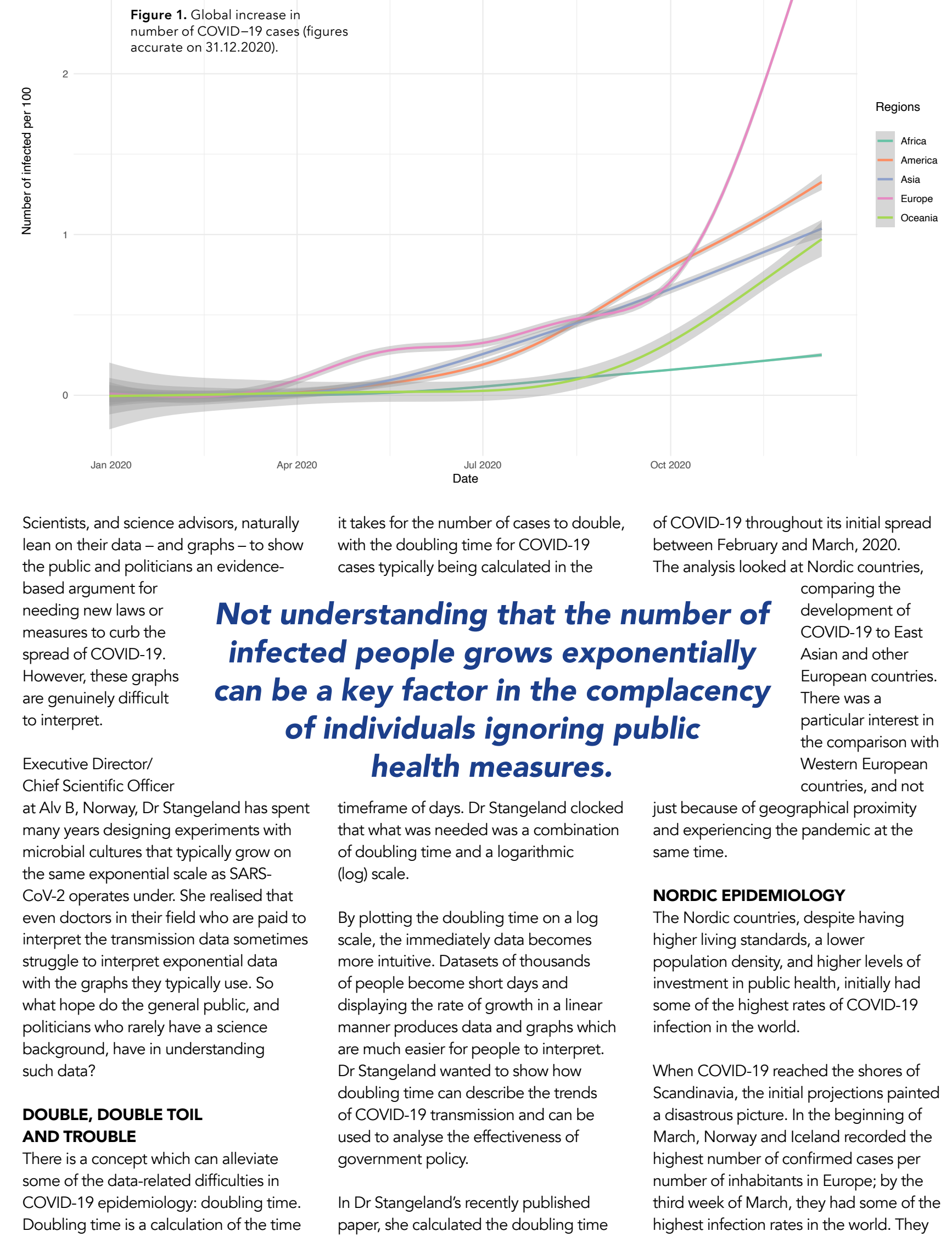




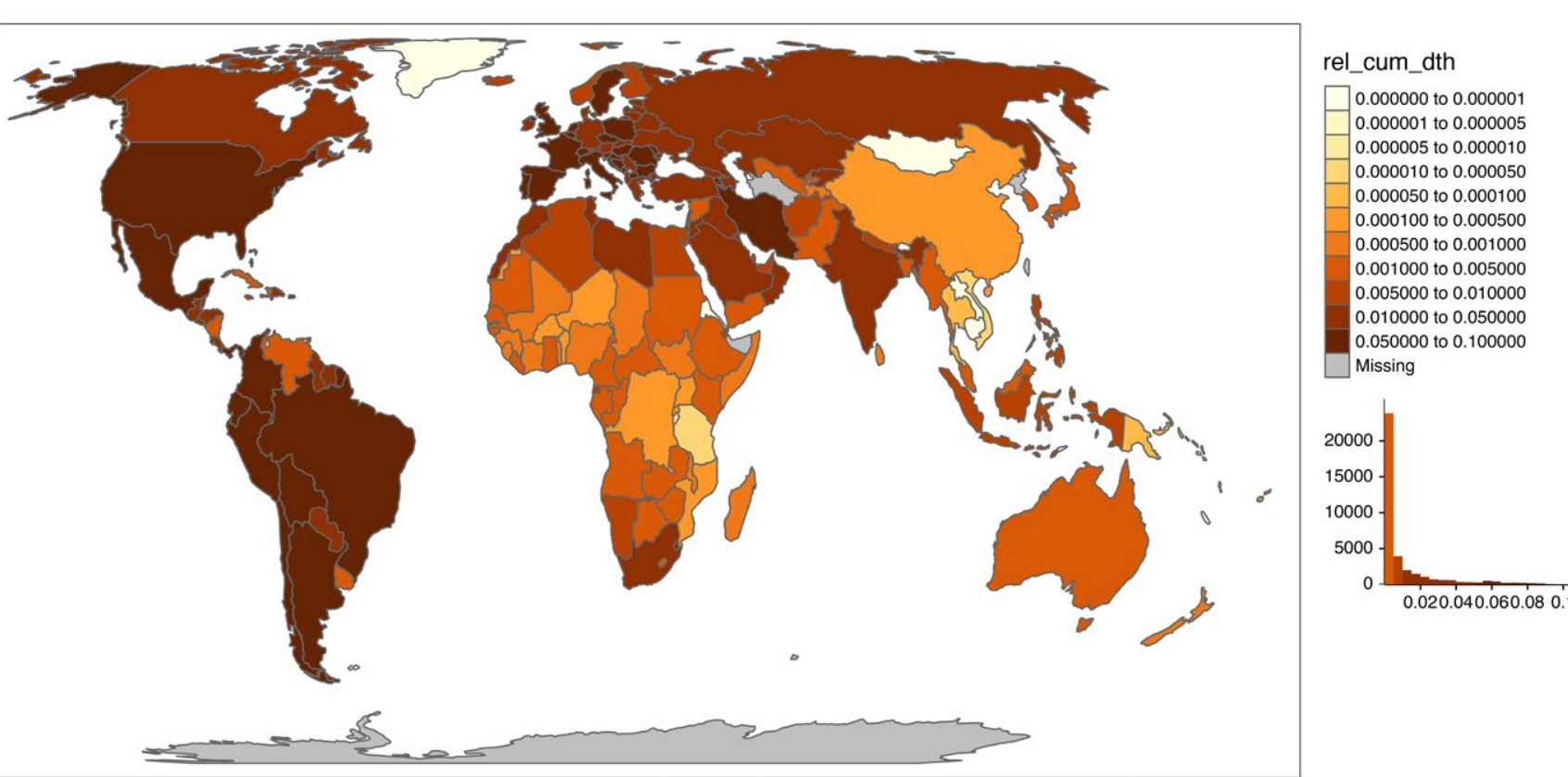

Figure 2. Cumulative number of COVID-19 related deaths corrected for the population size (in percentages, figures accurate on 31.12.2020)

were sharing this ignominious prize with Italy and Spain - countries that were soon to be known as the tragic epicentres of this would later be attributed to skiing tourists flying back from Italy and Austria.

In response, the Nordic governments implemented lockdown measures by mid-March, 2020, excluding Sweden. Norway grounded all non-essential trave closed schools, banned public gathering and enacted the policy of the 14-day self-quarantine for individuals displaying symptoms. Denmark and Iceland a so

It's the comparative analysis of infection It's the comparative analysis of infection
rates that enables the doubling time value data of COVID-19 cases; otherwise, the steep exponential curves of a liner scale (for case growth) causes difficulties in analysing and interpreting the data. Bu the direct doubling time value is very easy to understand - the longer period of time it takes your virus to double, the lower the number of cases.

Dr Stangeland's data shows that doubling time increased in all the Nordic countries since the 12th March 2020, when lockdown measures were first implemented. Denmark recorded the biggest improvement, as their doubling time increased from two to ten days. Due cases, particularly at the beginning of the doubling time of the COVID-19 mortality rate. This mortality rate could be compared as a control to test the reliability of the doubling time of the number of cases. As the mortality rate doubling time was similar to the number of cases, one can assume they're reliable.

These results showed a strong correlation between the lockdown measures, with the infrastructure, alongside stricter measures at the time, such as wearing face masks in public, which wasn't widespread during the first wave in Europe. Comparison mply that a higher doubling time means less cases.

Of course, there are exceptions Germany had lower mortality rates, despite having a lower doubling time, than other European countries like Italy doubling time decreasing in most Nordic and the UK. Nonetheless, this analysis -

...the longer period of time it takes your virus to double, the lower the number of cases.

countries roughly in line with government- published at the end of March last year enforced lockdown. This correlation (2020), provides a compelling case for is also found internationally, as South strict lockdown measures. Given the Korea's doubling time was significantly
better than most Nordic countries. South
countries like the United States and Brat Korea had better COVID-19 testing this hindsight makes it easy to agree.

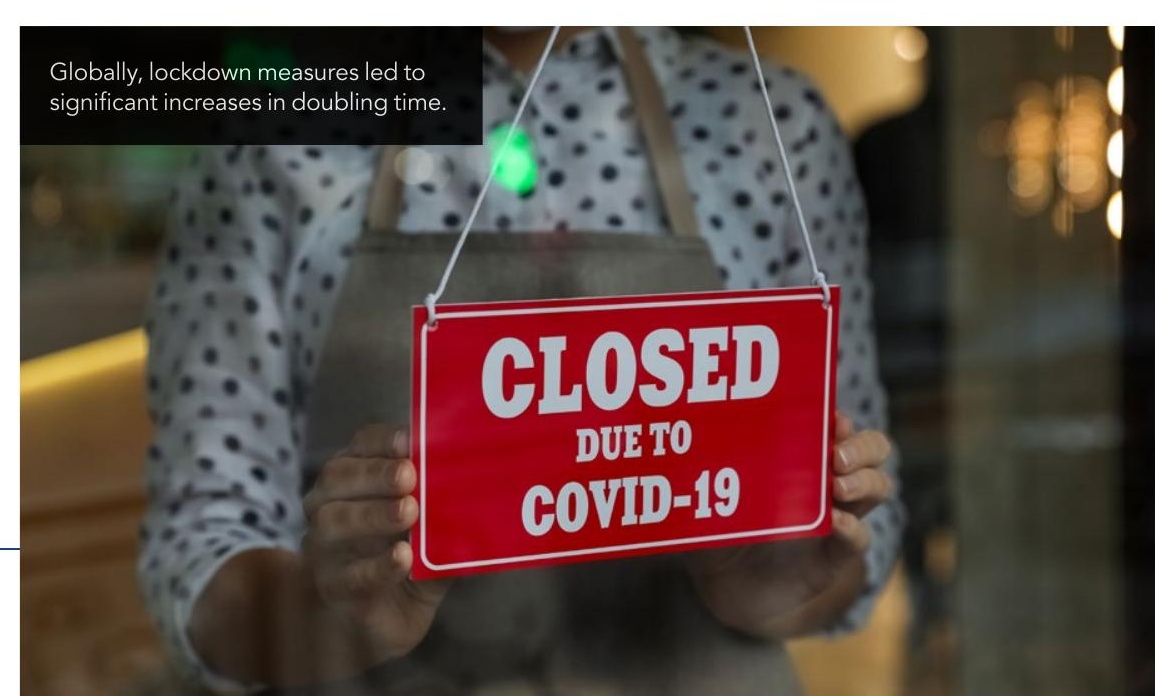
with East Asian countries ultimately Biljana Stangeland

E: Bilijana.stangeland@alvb.no T: $+4790152332 \quad$ W: http://biljanastangeland.no

Research Objectives

Biljana Stangeland's technology focus is on molecular biology, bioinformatics and data science.

\section{Detail}

\section{Address}

Pløensgate 1, 0181 Oslo, Norway

Bio

Biljana Stangeland is Executive Director/Chief Scientific Officer at Alv B, Norway. She has a PhD in Molecular Biology from Max-Planck institute in Germany. Following more than 25 successful years in academia working in cancer research and bioinformatics, and five years as a Lead Data Scientist and Biomedical Expert in the private sector, Biljana decided to dedicate herself to biomedica innovation and development of new experimental treatments for cancer.

Funding

Alv AS, https://alv.no

Collaborators

Alv AS, https://alv.no

Alv Biotechnology, https://alvb.no

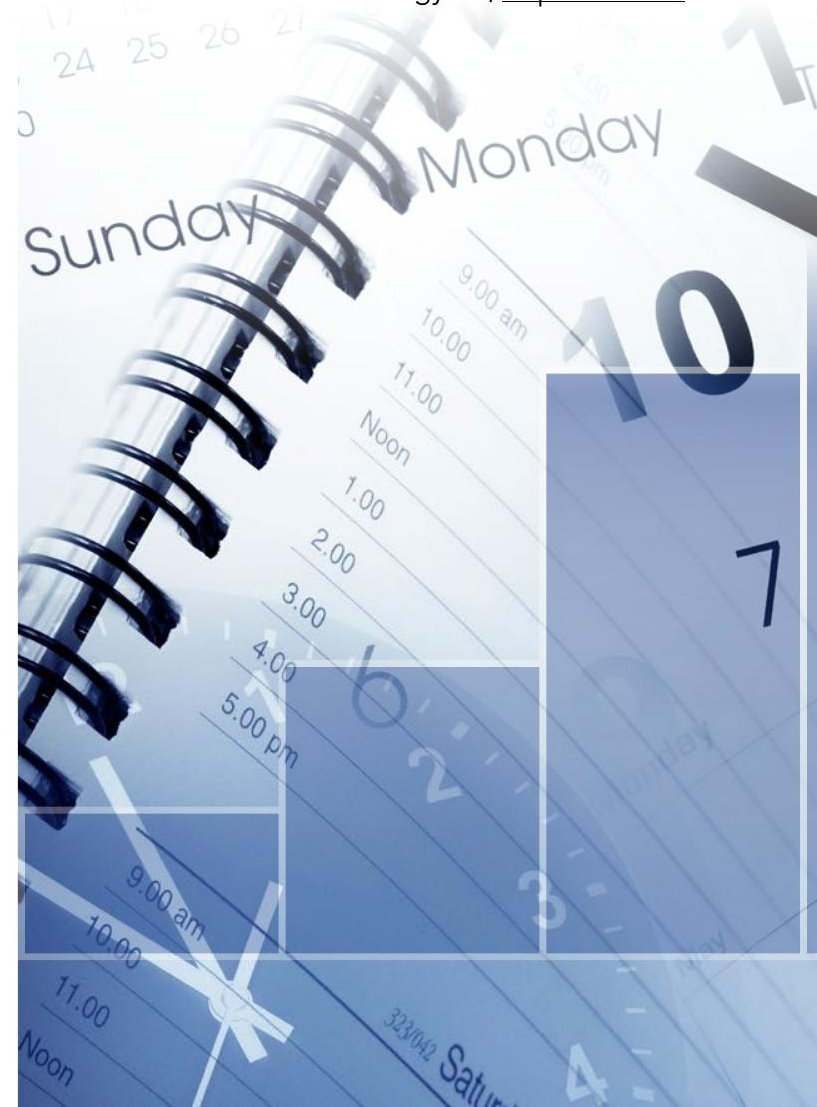

\section{References}

Stangeland, B. (2020). How to evaluate the success of the COVID-19 measures implemented by the Norwegian government by analyzing changes in doubling time. MedRxiv preprint. https://doi.org/10.1101/2020.03.29.20045187

\section{Personal Response}

What does subsequent doubling time data from the rest Wr 2020/2021 tell us about the public health approaches

II Doubling times-based predictions could still be used However lon the $14^{\text {th }}$ of December 2020 . switched from daily to weekly reporting. The subsequent doubling times can therefore be calculated only for longer periods of times thus averaging trends to 20-30 days. For more detailed predictions national daily transmission data
have to be downloaded and used.

To what extent could this approach with doubling time be used with other epidemics?

II This approach can indeed be used in any other comes to availability of transmission data. Not all diseases are as extensively tested as COVID-19. The method is quite robust with regard to systematic underreporting of cases as
long as the testing routines remain somewhat the same.

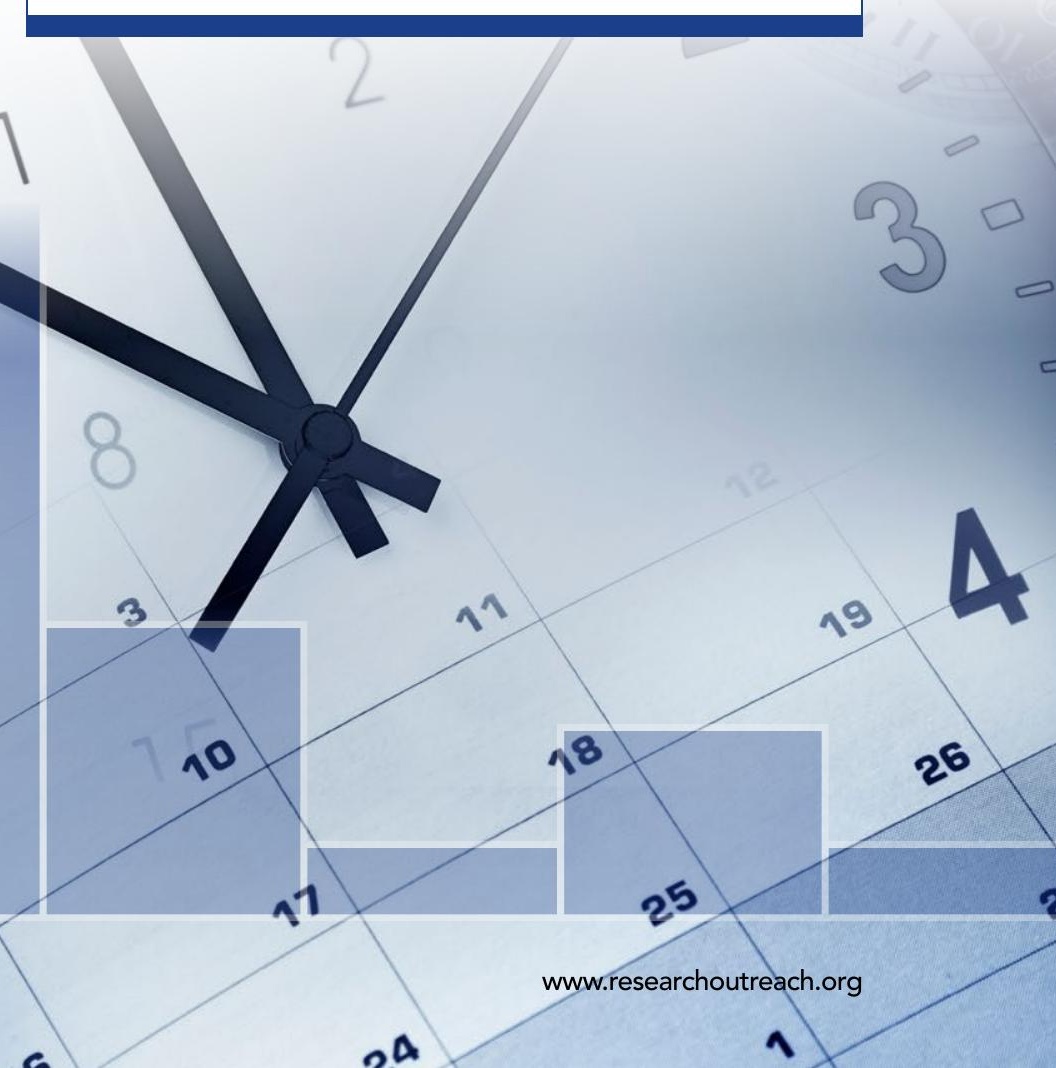

